\section{BMJ Paediatrics Open}

\title{
Exposure and attitudes to adolescent health amongst Paediatric trainees in Northern Ireland: a mixed- methods study
}

\author{
Stephen Mullen (D) , ${ }^{1}$ Michael D Shields, ${ }^{2}$ Dara O'Donoghue (D) ${ }^{3,4}$
}

To cite: Mullen S, Shields MD, O'Donoghue D. Exposure and attitudes to adolescent health amongst Paediatric trainees in Northern Ireland: a mixed-methods study. BMJ Paediatrics Open 2020;4:e000563. doi:10.1136/ bmjpo-2019-000563

Received 6 August 2019 Revised 21 January 2020 Accepted 30 January 2020

Check for updates

\section{(c) Author(s) (or their} employer(s)) 2020. Re-use permitted under CC BY-NC. No commercial re-use. See rights and permissions. Published by BMJ.

${ }^{1}$ Paediatric Emergency Department, The Royal Belfast Hospital for Sick Children, Belfast, UK

${ }^{2}$ Royal Belfast Hospital for Sick Children, Belfast, Northern Ireland

${ }^{3}$ Department of Child Health, Centre for Medical Education, Queens University Belfast, Belfast, UK

${ }^{4}$ Paediatric Respiratory Medicine, Royal Belfast Hospital for Sick Children, Belfast, UK

Correspondence to Dr Stephen Mullen; drsmullen@ gmail.com

\section{ABSTRACT}

Aims To determine the exposure and attitudes of paediatric trainees towards adolescent medicine. Methods All paediatric trainees in the Northern Ireland deanery $(n=107)$ were invited to participate in an online survey in March 2016. The questionnaire was based on the 'Modified Perceptions of Adolescent Issues and Resources: Care of Adolescents' questionnaire. The questions included a 5-point Likert scale (1-strongly disagree, 5-strongly agree) as well as open questions. All paediatric trainees were invited to attend focus groups to expand on themes generated from the questionnaire.

Results The response rate for the paediatric survey was $62 \%(n=66)$. Trainees identified adolescence as an area of importance similar to paediatrics and neonates; however, knowledge, confidence, skills and previous teaching in adolescent medicine were lower than for neonatal medicine and general paediatrics. Trainees who saw $\geq 6$ adolescent patients per week were more likely to rate the importance of adolescent medicine higher. Trainees' perceived confidence, knowledge, self-rated skills and prior teaching in adolescent medicine were strongly correlated. Most $(70 \%)$ respondents stated that they had not attended an adolescent transition clinic during their postgraduate training. Undergraduate and postgraduate teaching for adolescent health was rated poorly.

Conclusions This project identified a paediatric trainee population that are aware of the importance of adolescent health but with low perceived knowledge, skills and confidence to manage them. Education is required to enhance learning and improve outcomes for adolescent patients.

\section{INTRODUCTION}

Adolescence is the period when an individual transitions from childhood to adulthood. WHO and UNICEF define adolescence between 10 and 19 years old. ${ }^{2}$ Globally, this represents $16 \%$ of the world's population, equating to 1.2 billion people. ${ }^{2}$ In the UK, $13 \%-15 \%$ of the population fall within the adolescent age bracket. ${ }^{3}$

The mortality rate associated with adolescence remains high when compared with other age groups, with road traffic accidents, violence and self-harm the leading causes. ${ }^{3}$

\section{What is known about the subject?}

Adolescent healthcare is currently delivered by primary care, paediatric and adult services.

- Recommendations from the Royal Colleges state that trainees who manage adolescent health should have specific training in this field.

\section{What this study adds?}

Trainees identified adolescence as an area of importance similar to paediatrics and neonates.

- Knowledge, confidence, skills and previous teaching in adolescent medicine were lower than for neonatal medicine and general paediatrics.

- Adolescent medicine should be added to the undergraduate and postgraduate curricula.

While the perceived complexities associated with managing adolescent patients are well recognised, there exist unique opportunities to intervene in a positive manner with the potential to reduce the likelihood of developing a health condition in later life. ${ }^{4}$

The care for adolescent patients in the UK is delivered by general practitioners in primary care, and both paediatric and adult services in secondary care. In the acute setting, patients 16 years and under are generally seen by paediatric services with patients 16 years and over being attended by adult services. Practice can vary for adolescents with chronic illness, with paediatricians often continuing to see these patients beyond their 16th birthday. The need for a tailored UK training programme is recognised with recommendations that training in adolescent health should be mandatory for all Royal Colleges whose members may be involved in the care of young people..$^{5}$ It is not known what experience paediatric trainees in Northern Ireland (NI) have in this area. 
The primary aim of this study is to assess the current exposure, knowledge and confidence of NI paediatric trainees in adolescent medicine.

\section{METHODS}

This is a mixed-methods study employing quantitative and qualitative methodologies in the form of a survey and focus groups.

\section{Survey}

All paediatric trainees in the NI Deanery $(n=107)$ were contacted by email with a hyperlink to a survey in March 2016. The responses were anonymised. The questionnaire was based on the 'Modified Perceptions of Adolescent Issues and Resources: Care of Adolescents'. ${ }^{6}$ Permission was gained for the use of this tool from the author.

Using a 5-point Likert scale (1-strongly disagree, 5 strongly agree), the participants rated their knowledge, confidence, skill, previous teaching and perceived importance in managing patients in the following age brackets: neonatal $(<4 / 52)$, paediatric ( 1 month to 9 years), adolescent (10-19 years old) and adult ( $\geq 19$ years old). Using the same Likert scale and domains, the participants were asked further questions regarding specific adolescent conditions.

\section{Focus groups}

All paediatric trainees were invited to attend focus groups. The focus groups had a semistructured approach and were moderated (SM and DO) to encourage guided discussion. To facilitate moderation, survey responses were used to create a focus group guide. The discussions were recorded using two devices and transcribed verbatim. The data were reviewed independently by two members of the research team (SM, DO). Inductive analysis was used to identify emerging themes from the transcripts. ${ }^{7}$ The focus groups would terminate when thematic saturation was reached with a minimum number of two focus groups conducted.

\section{Patient and public involvement}

Patients and the public were not involved in the designing of this study.

\section{Statistical analysis}

Survey data for the five domains (importance, knowledge, confidence, skills and prior teaching) were described using median values.

For analysis Likert score (1-5), the data were rescaled so that a rating of 5 equates to 100 and a rating of $1-0$. Previous exposure to adolescent patients was classified as $0,1-5, \geq 6$ patients/week and compared with the above domains using a one-way analysis of variance (ANOVA). If the ANOVA result was statistically significant, a TukeyKramer post hoc analysis was used. A p $<0.05$ was used to indicate statistical significance.

Determination of linear association between principal domains was performed using Pearson's correlation coefficient $(r)$. A correlation coefficient $>0.6$ was taken as showing a strong association between variables.

Data were analysed using SAS JMP V.14.0 (SAS).

\section{RESULTS}

\section{Survey}

A total of 66 trainees $(62 \%)$ responded to the questionnaire, but not all completed the full survey (ranging from 66 for demographic data to 53 for specific topics, please see tables 1 and 2). In terms of demographics, $83 \%$ of responders were female, $44 \%$ were from the junior tier (ST1-3) and 56\% the middle grade tier (ST4-8) (table 3).

In an average week, $57 \%$ of trainees stated they cared for between 1 and 5 adolescent patients, 20\% stated 6-10 patients, $5 \%$ more than 10 patients and $18 \%$ stating they had no regular weekly contact with adolescent patients. Trainees who see $\geq 6$ adolescents/week were more likely to rate the importance of adolescent medicine higher $(\mathrm{p}=0.015)$ although they did not feel that they had any greater knowledge $(p=0.4)$, confidence $(p=0.34)$, skills $(0.35)$ or prior teaching $(\mathrm{p}=0.23)$ in adolescent medicine.

Trainees identified adolescence as an area of importance similar to paediatrics and neonates; however, knowledge, confidence, skills and previous teaching in adolescent medicine were lower than for neonatal medicine and general paediatrics (table 1).

The questionnaire also focused on specific areas of adolescent health (table 2). In contrast to the other

\begin{tabular}{|c|c|c|c|c|c|c|}
\hline Topic & $\begin{array}{l}\text { No of } \\
\text { responses }\end{array}$ & Importance & Knowledge & Confidence & Skill & $\begin{array}{l}\text { Prior } \\
\text { teaching }\end{array}$ \\
\hline Managing neonatal patients $(<4 / 52)$ & 53 & 5 & 4 & 4 & 4 & 4 \\
\hline Managing paediatric patients ( 1 month to 9 years) & 53 & 5 & 4 & 4 & 4 & 4 \\
\hline Managing adolescent patients (10-19 years old) & 53 & 5 & 3 & 3 & 3 & 3 \\
\hline Managing adult patients $(>20)$ & 53 & 3 & 3 & 3 & 3 & 3 \\
\hline
\end{tabular}

Using a 5-point Likert scale (1-strongly disagree, 5-strongly agree), the participants rated their perceived importance, knowledge, confidence, skill and previous teaching. 
Table 2 Median ratings for to importance, knowledge, confidence, skill and prior teaching by paediatric trainees from Northern Ireland by topic

\begin{tabular}{|c|c|c|c|c|c|c|}
\hline Topic & $\begin{array}{l}\text { No of } \\
\text { responses }\end{array}$ & Importance & Knowledge & Confidence & Skill & $\begin{array}{l}\text { Prior } \\
\text { teaching }\end{array}$ \\
\hline Growth and puberty during adolescence & 59 & 5 & 3 & 3 & 3 & 2 \\
\hline Nutrition and obesity & 59 & 4 & 3 & 3 & 3 & 2 \\
\hline Exercise & 59 & 4 & 3 & 3 & 3 & 2 \\
\hline Sexual and reproductive health & 59 & 5 & 3 & 2 & 2 & 2 \\
\hline Peer relations & 59 & 4 & 3 & 3 & 3 & 2 \\
\hline Adherence issues & 56 & 5 & 3 & 3 & 3 & 2.5 \\
\hline Psychosomatic complaints & 56 & 4 & 3 & 3 & 3 & 2 \\
\hline Common menstrual problems & 56 & 4 & 3 & 3 & 3 & 2 \\
\hline Adolescent mental health & 56 & 5 & 3 & 3 & 3 & 2 \\
\hline Eating disorders & 56 & 5 & 3 & 3 & 3 & 2 \\
\hline Substance use and misuse & 56 & 4 & 3 & 3 & 2 & 2 \\
\hline Transitional care & 56 & 5 & 3 & 3 & 3 & 2 \\
\hline $\begin{array}{l}\text { Injuries and violence including accidents, } \\
\text { self-harm, abuse }\end{array}$ & 56 & 4 & 3 & 3 & 3 & 2 \\
\hline $\begin{array}{l}\text { Confidentiality, consent, rights, access and } \\
\text { personal advocacy }\end{array}$ & 56 & 5 & 3 & 3 & 3 & 3 \\
\hline $\begin{array}{l}\text { Impact of the environmental context: } \\
\text { socioeconomic, cultural, ethnic and gender } \\
\text { issues }\end{array}$ & 55 & 4 & 3 & 3 & 3 & 2 \\
\hline $\begin{array}{l}\text { Issues concerning resources, resilience, } \\
\text { exploratory and risk-taking behaviours }\end{array}$ & 53 & 4 & 3 & 3 & 2 & 2 \\
\hline $\begin{array}{l}\text { Health education and promotion including } \\
\text { school health for adolescents }\end{array}$ & 54 & 4 & 3 & 3 & 3 & 2 \\
\hline Adolescent asthma & 53 & 5 & 4 & 4 & 3 & 3 \\
\hline
\end{tabular}

Using a 5-point Likert scale (1-strongly disagree, 5-strongly agree), the participants rated their perceived importance, knowledge, confidence, skill and previous teaching.

domains, perceived importance had a median rating of $\geq 4$ for all areas.

The majority of trainees rated their undergraduate and postgraduate teaching in adolescent medicine as poor (undergraduate $73 \%$ and postgraduate $75 \%$ ). Most $(70 \%)$ participants stated they had not attended an

Table 3 Demographic characteristics of respondents

\begin{tabular}{llll}
\hline & & No & $\begin{array}{l}\text { Percentage } \\
\text { (\%) }\end{array}$ \\
\hline $\begin{array}{lll}\text { Gender } \\
(\mathrm{n}=66)\end{array}$ & Male & 11 & 17 \\
Seniority & Junior tier (ST1-3) & 29 & 44 \\
$(\mathrm{n}=66)$ & Middle grade tier & 37 & 56 \\
& $($ ST4-8) & & \\
No of & 0 & 12 & 18 \\
adolescents & $1-5$ & 37 & 57 \\
seen per & $6-10$ & 13 & 20 \\
week $(\mathrm{n}=65)$ & 35 & 5 \\
& $>10$ & 3 & \\
\hline
\end{tabular}

adolescent transition clinic during postgraduate training. The HEEADSSS (Home, Education/Employment, Eating, Activities, Drugs, Sexuality, Suicidal ideation and Safety) assessment tool had been used by $10 \%$ of respondents with $50 \%$ stating they were not aware of it. The adolescent e-learning modules accessed via 'e-learning for Healthcare' had been completed by $10 \%$ of respondents.

The majority of trainees deemed that adolescent patients would be best managed by a paediatrician with a specialist interest (77\%) with $15 \%$ stating an adult physician with a special interest and $8 \%$ a general paediatrician. No trainee opted for a general adult physician.

The five domains were analysed to determine any linear association (table 4). Knowledge, confidence, skill and prior teaching were strongly correlated with each other. However, each of these was only weakly-moderately correlated with importance.

\section{Focus groups}

There were 15 members in each focus group and thematic saturation occurred following completion of two focus groups. Analysis of focus group transcripts identified three distinct overarching themes. The initial 
Table 4 Correlation analysis for the five principal domains (importance, knowledge, confidence, skill, prior teaching)

\begin{tabular}{|c|c|c|c|c|c|}
\hline & Importance & Knowledge & Confidence & Skill & Prior teaching \\
\hline \multicolumn{6}{|l|}{ Importance } \\
\hline Knowledge & 0.47 & & & & \\
\hline Confidence & 0.44 & 0.93 & & & \\
\hline Skill & 0.42 & 0.85 & 0.97 & & \\
\hline Prior teaching & 0.27 & 0.65 & 0.76 & 0.79 & \\
\hline
\end{tabular}

A correlation coefficient, $r>0.6$ is taken as showing a strong association between variables.

theme was that adolescent health was important. 'There is a tendency for risky behaviour, requiring early intervention to prevent long-term health problems'. It was commented that 'adolescents seemed to be an afterthought, adult physicians are prepared to manage adult patients in a suitable environment and the same can be said of paediatric patients, however, neither have fully addressed the needs of adolescents'.

The second theme to emerge was that adolescent services are currently inadequate. 'We can stabilise them, but we don't know where they are going to go, we do not have the support to look after them properly'. 'There is nowhere to see patients in a private or confidential manner. Pulling the curtain in a four-bed cubicle is not sufficient to discuss personal issues'.

The final theme to emerge was that the participants regarded their training in adolescent health as poor. A senior trainee stated 'I don't feel like I have been trained to deal with adolescent health. There is no formal training, no specialist team or designated area to assess these young people. I feel I have to use a common sense approach to these cases'.

The focus group discussed solutions to improve training. These included dedicated undergraduate teaching as well as improved postgraduate exposure in the form of ward-based teaching and specialist training days.

\section{DISCUSSION}

Trainees identified adolescence as an area of importance with a ratings similar to that of neonates and general paediatrics. The knowledge, confidence, skills and previous teaching were noted to be lower in the adolescent bracket compared with the neonatal and paediatric values.

For specific adolescent conditions, the results followed a trend, with perceived importance consistently scoring higher than confidence, skill and prior teaching. This included conditions that have featured significantly in recent media reports, including mental health, substance abuse, sexual health and obesity. ${ }^{89}$ These are areas that that would be expected to generate high mean scores across each domain. Interestingly, one of the areas that generated the lowest mean score for importance was risk-taking behaviours. Given the impact of risk-taking behaviour on adolescent morbidity and mortality, this is an area where further education is paramount. There was a correlation between the confidence, knowledge and skills that participants rated themselves in adolescent medicine. It is important to acknowledge the interdependencies of each domain and the implications this may have on training.

There has been increasing interest in adolescent health, driven by multiple factors including mortality and the rise in knife crime and gang violence. ${ }^{10}$ Recent publications have suggested that adolescence should span the age range from 10 to 24 years in response to 'recognised shifts in events of biological growth and social role transitions. ${ }^{11} 12$ If this new definition of adolescence is adopted, this cohort of patients would represent $18 \%$ of the current UK population. ${ }^{3}$ Adolescent mortality accounts for between 2000 and 3000 deaths each year within the UK. ${ }^{13}$ Although, the overall mortality rate for adolescents remains low, there is a concerning trend. While there has been a reduction in mortality over the last 20 years, the rate is now static, with an actual increase in mortality rates in certain subsets. ${ }^{1415}$

The needs of the adolescent population and taking the opportunities to intervene in a positive manner have been embraced by other nations, recognising adolescent health as a subspecialty and implementing bespoke training packages. Australia and the USA are at the forefront of these initiatives and, while the UK has started to make positive steps including offering paediatric specialty training packages, there is still much work to be done to equip our health service and staff to meet the needs of adolescent patients.

In response to the educational and training deficiencies related to adolescent healthcare, the NI deanery has taken active steps to start to address them. These include the addition of an undergraduate e-learning package and postgraduate training which were mapped to their respective curricula.

There are some limitations to this study. The response rate of $62 \%$ may not be fully representative of the trainee cohort. No data on the non-respondents were collected to compare, with the potential that this was biased sample. The study was conducted in 2016 and may not correlate to the current cohort of trainees. However, it is this authors' opinion that the results remain relevant, re-enforcing the need for ongoing education and initiatives to highlight adolescent healthcare. The study was confined to NI so the results may not be generalisable to other geographical locations. It 
is our hope that the results of this study will encourage other training bodies to review their current practices and embed adolescent specific training in their respective training schemes.

\section{Twitter Stephen Mullen @dr_smullen}

Acknowledgements Dr Mike Stevenson, Dr Stan Craig and Dr A Thompson.

Contributors SM developed and lead on this project, authoring the manuscript. MS performed data analysis and contributed to the final manuscript. DO supervised the project and contributed to the final manuscript.Implications and contribution: Paediatric trainees are aware of the importance of but feel unprepared to deal with adolescent patients; Paediatric trainees in Northern Ireland rate their undergraduate and postgraduate teaching in adolescent health as poor; Paediatric trainees in Northern Ireland feel that adolescents would be optimally managed by a paediatrician with a specialist interest in adolescent health.

Funding The authors have not declared a specific grant for this research from any funding agency in the public, commercial or not-for-profit sectors.

Competing interests None declared.

Patient consent for publication Not required.

Ethics approval Ethical approval was granted by Queen's University Belfast School of Medicine and Dentistry Research Ethics Committee (SMDBS Research Ethics Number: 15.13v2).

Provenance and peer review Not commissioned; externally peer reviewed.

Data availability statement Data are available on reasonable request. Data is held by SM and obtained by emailing on request.

Open access This is an open access article distributed in accordance with the Creative Commons Attribution Non Commercial (CC BY-NC 4.0) license, which permits others to distribute, remix, adapt, build upon this work non-commercially, and license their derivative works on different terms, provided the original work is properly cited, appropriate credit is given, any changes made indicated, and the use is non-commercial. See: http://creativecommons.org/licenses/by-nc/4.0/.

\section{ORCID iDs}

Stephen Mullen http://orcid.org/0000-0001-7115-980X

Dara 0'Donoghue http://orcid.org/0000-0001-5046-2092

\section{REFERENCES}

1 World Health Organisation. Health for the world's adolescents: a second chance in the second decade, 2014. Available: http://www. who.int/maternal child adolescent/documents/second-decade/en/

2 United Nations Children's Fund (UNICEF). Adolescent overview. Available: https://data.unicef.org/topic/adolescents/overview/ [Accessed Oct 2019].

3 Hagell A, Shah R. Key Data on Young People 2019. Association for Young People's Health, 2019. Available: http://www. youngpeopleshealth.org.uk/key-data-on-young-people [Accessed Oct 2019].

4 Pringle J, Mills K, McAteer J, et al. A systematic review of adolescent physiological development and its relationship with health-related behaviour: a protocol. Syst Rev 2016;5:3.

5 Tylee A, Haller DM, Graham T, et al. Youth-friendly primary-care services: how are we doing and what more needs to be done? Lancet 2007;369:1565-73.

6 McDonagh JE, Southwood TR, Shaw KL, et al. Unmet education and training needs of rheumatology health professionals in adolescent health and transitional care. Rheumatology 2004;43:737-43.

7 Thomas DR. A general inductive approach for analyzing qualitative evaluation data. Am J Eval 2006;27:237-46.

8 Schraer R. Is young people's mental health getting worse? Available: https://www.bbc.co.uk/news/health-47133338 [Accessed Oct 2019].

9 BBC. Record number of severely obese children. Available: https:// www.bbc.co.uk/news/health-44926893 [Accessed Oct 2019].

10 Butcher B, Corker S, Stephenson W. The places knife crime is rising fastest. Available: https://www.bbc.co.uk/news/uk-49923129? intlink_from_url=https://www.bbc.co.uk/news/topics/c12kgl2e4g6t/ knife-crime\&link_location=live-reporting-story [Accessed Oct 2019].

11 Sawyer SM, Azzopardi PS, Wickremarathne D, et al. The age of adolescence. Lancet Child Adolesc Health 2018;2:223-8.

12 Silver K. Adolescence now lasts from 10 to 24. Available: https:// www.bbc.co.uk/news/health-42732442 [Accessed 25 May 2019].

13 Office for National Statistics. Deaths by single year of age tables - UK, 2018. Available: https://www.ons.gov.uk/peoplepopula tionandcommunity/birthsdeathsandmarriages/deaths/ datasets/ deathregistrationssummarytablesenglandandwalesdeathsby singleyearofagetables [Accessed Oct 2019].

14 Shah R, Hagell A, Cheung R. International comparisons of health and wellbeing in adolescence and early adulthood. London: Nuffield Trust, 2019

15 Wolfe I, MacFarlene A, Donkin A, et al. Why children die- death in infants, children and young people in the UK- 2014. Available: https://www.rcpch.ac.uk/resources/why-children-die-researchrecommendations 